УДК 504.06, https://doi.org/10.37878/2708-0080/2021-2.08

\title{
АНАЛИЗ И УПРАВЛЕНИЕ ЭКОЛОГИЧЕСКИМИ РИСКАМИ В НЕФТЕГАЗОВОЙ СФЕРЕ
}

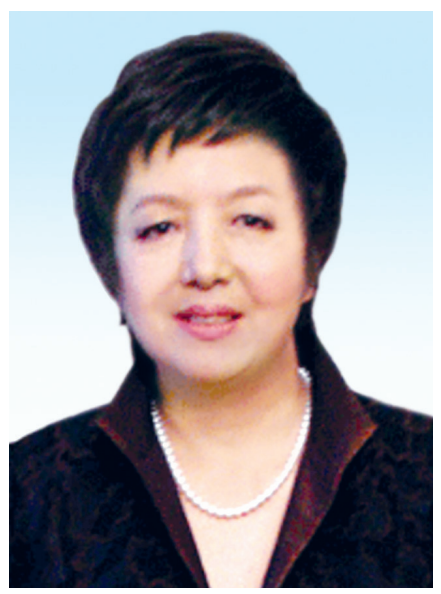

Ж.Р. ТОРЕГОЖИНА, профрессор кафедры ЮНЕСКО и Устойчивое развитие, https://orcid.org/0000-00032419-7920

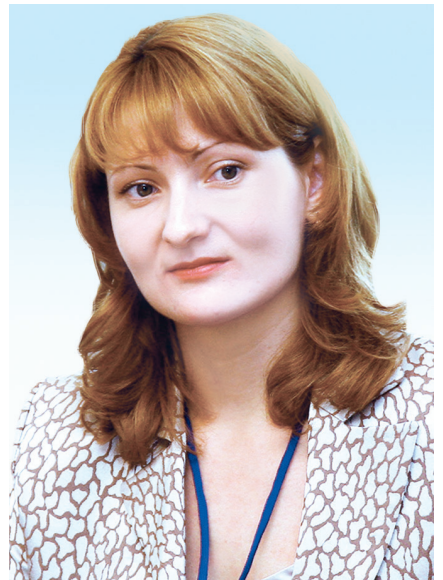

Е.В. СОЛОДОВА,

и.о. доцента кафедры ЮНЕСКО и Устойчивое развитие, https://orcid.org/0000-00030136-4220

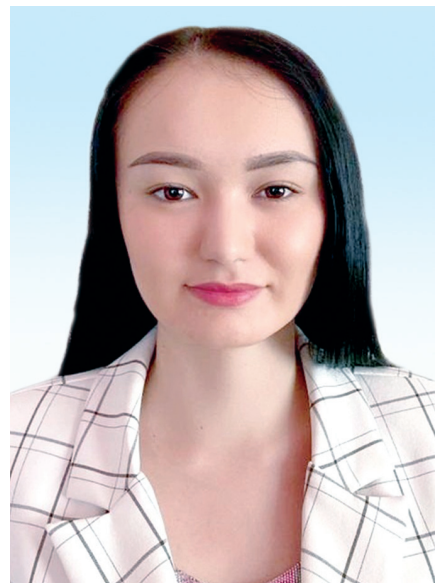

Ш. ACKAP, магистрант, https://orcid.org/0000-00021053-5733

КАЗАХСКИЙ НАЦИОНАЛЬНЫЙ УНИВЕРСИТЕТ ИМ. АЛЬ-ФАРАБИ Республика Казахстан, 050040, г. Алматы, пр. аль-Фараби, 71

Авторами поведен анализ современного состояния управления экологическими рисками в нефртегазовой сфрере Республики Казахстан. Установлено, что в настоящее время не существует полного определения понятия «экологический риск» и отсутствует единая методика проведения оценки экологического риска.

Рассмотрены возможные экологические риски, возникающие при разработке месторождения, добыче сырья, транспортировке и др. Выяснено, что масштабное негативное воздействие происходит при авариях на объектах. В таких ситуациях важна роль законодательных и нормативных документов, которые должны содержать гарантии и критерии недопущения чрезвычайных ситуаций, а в случае критического положения предусматривать действенные меры выхода из них с минимизацией возможных потерь.

Авторами отмечено, что вопросы экологической безопасности требуют скорейшего освоения и нормативно-законодательного офрормления. Международный и казахстанский опыт в области анализа, оценки и управления экологическими рисками убедительно показывает, что с каждым годом решение таких задач становится все более актуальным не только для общества в целом, но и для отдельных организаций, являющихся объектами недропользования.

КЛЮЧЕВЫЕ СЛОВА: окружающая среда, экологическая безопасность, риск, техногенные системы, управление экологическими рисками, нефтегазовая сфера, устойчивое развитие. 


\title{
МҰНАЙ-ГАЗ САЛАСЫНДАҒЫ ЭКОЛОГИЯЛЫҚ ТӘУЕКЕЛДЕРДІ ТАЛДАУ ЖӘНЕ БАСҚАРУ
}

Ж.P. ТОРЕГОЖИНА, ЮНЕСКО және тұрақты даму кафедрасының профессоры, https://orcid. org/0000-0003-2419-7920

Е.В. СОЛОДОВА, ЮНЕСКО және тұрақты даму кафедрасы доцентінің міндетін атқарушы, https://orcid.org/0000-0003-0136-4220

Ш. АСҚАР, магистрант, https://orcid.org/0000-0002-1053-5733

\author{
ӘЛ-ФАРАБИ АТЫНДАҒЫ ҚАЗАҚ ҰЛТТЫҚ УНИВЕРСИТЕТІ \\ Қазақстан Республикасы, Алматы, 050040, әл-Фараби даңғылы, 71
}

Авторлар Қазақстан Республикасындағы мұнай-газ саласындағы экологиялық тәуекелдерді басқарудың қазіргі жай-күйіне талдау жасады. Қазіргі уақытта "экологиялық тәуекел" ұғымының толық анықтамасы жоқ және экологиялық тәуекелді бағалауды жүргізудің бірыңғай әдістемесі жоқ екендігі анықталды.

Кен орнын игеру, шикізат өндіру, тасымалдау және т.б. кезінде туындауы мүмкін экологиялық қауіптер қарастырылды, объектілердегі авариялар кезінде ауқымды теріс әсер болатындығы анықталды. Мұндай жағдайларда заңнамалық және нормативтік құжаттардың рөлі маңызды, оларда Төтенше жағдайларға жол бермеудің кепілдіктері мен критерийлері қамтылуға, ал қиын жағдайда ықтимал шығындарды барынша азайта отырып, олардан шығудың пәрменді шаралары көзделуге тиіс.

Авторлар экологиялық қауіпсіздік мәселелері тез игеруді және нормативтік-заңнамалық ресімдеуді талап ететінін атап өтті. Экологиялық тәуекелдерді талдау, бағалау және басқару саласындағы халықаралық және қазақстандық тәжірибе жыл сайын мұндай міндеттерді шешу жалпы қоғам үшін ғана емес, жер қойнауын пайдалану объектілері болып табылатын жекелеген ұйымдар үшін де өзекті бола түсетінін айқын көрсетіп отыр.

ТҮЙІн СӨзДЕР: қоршаған орта, экологиялық қауіпсіздік, тәуекел, техногендік жүйелер, экологиялық тәуекелдерді басқару, Мұнай-газ саласы, тұрақты даму.

\section{ENVIRONMENTAL RISK ANALYSIS AND MANAGEMENT IN THE OIL AND GAS SECTOR}

ZH.R. TOREGOZHINA, Professor of UNESCO and Sustainable Development Department, https://orcid.org/0000-0003-2419-7920

YE.V. SOLODOVA, Acting Associate Professor of UNESCO and Sustainable Development Department, https://orcid.org/0000-0003-0136-4220

SH. ASKAR, master's degree student, https://orcid.org/0000-0002-1053-5733

AL-FARABI KAZAKH NATIONAL UNIVERSITY

71 al-Farabi Ave., Almaty, 050040, Republic of Kazakhstan

The authors analyze the current state of environmental risk management in the oil and gas sector in the Republic of Kazakhstan. It is established that at present there is no complete definition of the concept of "environmental risk" and there is no unified methodology for conducting an environmental risk assessment.

Possible environmental risks arising during the development of the field, extraction of raw materials, transportation, etc. are considered. It was found that a large-scale negative impact occurs during accidents at facilities. In such situations, the role of legislative and regulatory documents is important, which should contain guarantees and criteria for avoiding emergency situations, and in the case of a critical situation, provide effective measures to overcome them with minimizing possible losses.

The authors noted that the issues of environmental safety require early development and regulatory and legislative registration. International and Kazakhstani experience in the field of analysis, assessment and management of environmental risks clearly shows that every year the 
solution of such problems becomes more and more relevant not only for society as a whole, but also for individual organizations that are objects of subsurface use.

KEYWORDS: environment, environmental safety, risk, technogenic systems, environmental risk management, oil and gas sector, sustainable development.

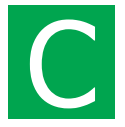

егодня управление экологическими рисками является необходимым элементом процесса обеспечения экологической безопасности в стране.

Общеизвестно, что в нефтегазовой сфере существует высокая степень экологических рисков - от разработки месторождения, добычи сырья и первичной обработки до использования конечного продукта и размещения отходов [1-4].

Актуальность исследования обусловлена тем, что понятие «экологический риск» является относительно новым для стран постсоветского пространства, включая Республику Казахстан.

Оценка воздействия экологических рисков на окружающую среду как стадия управления экологическими рисками сформировалась в начале 1970-х гг., с принятием в 1969 г. Акта о Национальной политике по охране окружающей среды в США. С тех пор она превратилась в мощный предупредительный инструмент, широко применяющийся в практике экологического регулирования в более чем 100 странах мира [2].

В настоящее время не существует достаточно полного определения понятия «экологический риск», которое в полной мере бы отражало его суть и, следовательно, каждый автор трактует это понятие исходя из своих интересов или области познания. Помимо этого, отсутствует единая методика проведения оценки экологического риска. В научной литературе [4-7] понятие риск имеет множество определений и трактовок, так, например в большинстве случаев под риском понимается возможная опасность потерь, связанных со спецификой тех или иных явлений природы и видов деятельности человеческого общества. Поэтому, необходима классификация экологических рисков, которая может проводиться по различным критериям, например, по степени распространения (риски могут быть глобальными и локальными), по степени их восприятия и воздействия (риски для здоровья людей, риски для недр, земли, водоемов, лесов и т.д.).

Сфера недропользования является одной из отраслей экономики, где существует высокая степень экологических рисков, особенно при разработке месторождений углеводородного сырья [1].

Экологические проблемы и риски с каждым годом становятся все более актуальными не только для общества в целом, но и для недропользователей, являющимися объектами экологического контроля со стороны уполномоченных государственных органов. Субъекты этих отношений подразделяются на две основные группы. К первой группе относятся различные государственные органы республиканского и местного уровня. В состав второй группы входят недропользователи и подрядчики/ субподрядчики. Все субъекты, входящие в первую и вторую группу, имеют непосредственное отношение к экологическим рискам. Причем субъекты первой группы в большой степени выступают как контролирующие, разрешающие и сдерживающие органы, а субъекты второй группы - как потенциальные источники экологических 
опасностей и угроз. Тем не менее, для тех и других большое значение имеет рациональное управление экологическими рисками, с которыми они сталкиваются в своей деятельности.

Экологический кодекс РК содержит нормы, устанавливающие общие принципы государственного регулирования в области охраны окружающей среды и в области использования природных ресурсов. Экологическое законодательство предусматривает и систему общественного контроля за деятельностью природопользователей и обеспечивает доступность экологической информации для населения. Однако, в сфере регулирования экологических отношений множество проблем, связанных с отсутствием простых правил взаимодействия государственных уполномоченных органов и природопользователей по обеспечению устойчивой модели производства и потребления, противоречивостью положений нормативных правовых актов, отсутствием единообразной, объективной и справедливой правоприменительной практики [1].

В методическом пособии «Методы анализа экологического риска» [8] автор описывает анализ рисков, они различаются по типу и полноте исходной информации и решаемым задачам. По типу и полноте исходной информации различают качественный и количественный виды анализа риска.

Качественный анализ риска предназначен для определения факторов риска и обстоятельств, приводящих к рисковым ситуациям. Он включает в себя: выявление источников и причин риска; идентификацию всех возможных рисков; выявление практических выгод и возможных негативных последствий, которые могут наступить при реализации содержащего риск решения; ранжирование рисков по экспертным данным.

Качественный анализ позволяет выделить наиболее значимые риски, которые будут являться объектом дальнейшего количественного анализа.

Количественный анализ риска предполагает количественное определение отдельных рисков и риска проекта (принимаемого решения) в целом.

По решаемым задачам анализ риска включает его идентификацию, оценивание и прогноз.

Идентификация риска - это выявление рисков, характерных для определенного вида деятельности, причин их возникновения, форм проявления и рискообразующих факторов. Идентификация основана на анализе статистических данных об опасных явлениях и результатах их взаимодействия с антропосферой.

Оценивание риска включает оценку риска и определение его приемлемости путем сравнения с допустимым уровнем. Оценка риска заключается в количественном измерении фактического уровня показателя риска. Допустимый риск это риск, который в данном контексте считается допустимым при существующих общественных ценностях.

Прогноз риска - это оценка риска на определенный момент времени в будущем с учетом тенденций изменения условий его проявления [9].

В работе «Экологические риски. Теория и практика» классифицируют экологические риски на 2 варианта. Первый базируется на использовании 3 понятий - субъект риска, объект риска и предмет риска в контексте спектра потенциальных экономических ущербов. В этом варианте экологические риски классифицируются по родам. 
Экологические риски первого рода обусловлены негативным влиянием экосистем или их отдельных частей на экономическую деятельность. Экологические риски второго рода связаны с экологическими опасностями,возникающими в процессе негативного воздействия на экосистемы в условиях нормальной экономической деятельности в штатном режиме. Эти опасности подразделяются на прямые и косвенные. Экологические риски третьего рода связаны с экологическими опасностями, которые вызываются авариями и катастрофами технических систем, а также с залповыми выбросами и сбросами загрязняющих веществ. Во втором варианте классификации принимается во внимание, что риски, угрожающие безопасности населения, обычно характеризуются малыми вероятностями, но тяжелыми последствиями [14].

Автор в своей работе «Современные методы оценки рисков в экологии» [3] подробно описывает методику анализа риска, разработанную американским агентством по охране окружающей среды (Environmental Protection Agency of USA - U.S. EPA). Данная методика успешно применяется в США. ЕРА разрабатывает и применяет методы анализа риска с целью решения проблем загрязнения и защиты от загрязнений окружающей среды с целью изучения проблем загрязнения в производственной деятельности и загрязнения продуктов, соответственно своим названиям.

Первоначально ЕРА начало разработки методик анализа риска с целью определения критериев и стандартов для химических веществ, загрязняющих воды, затем был распространен на все другие среды. Большинство критериев были разработаны на основе экстраполяции данных, полученных в экспериментах на животных, и данных о дыхании, потреблении воды, пищи и усредненном весе человека.

Анализ химического риска обычно делится на 4 шага:

1 - Идентификация опасностей (загрязнителя). Идентификация потенциально токсического химического вещества;

2 - Определение отношения «доза-ответ». Определение токсикологических свойств в зависимости от пути поступления - оральный, ингаляционный или другой - в организм человека. Отношение доза-ответ обычно определяют на экспериментах с животными;

3 - Оценка экспозиции. Определение количества химического вещества в окружающей природе и его поступления в организм человека. Количество химического вещества поступившего в организм человека определяют путём установления количества химиката в окружающей природе и путей его транспорта (миграции). Суммарное количество токсиканта, который может нанести вред здоровью отдельного индивидуума или популяции, определяют путём количественной оценки поступления с пищей, воздухом и дермального контакта;

4 - Оценка риска. Оценка риска состоит в обработке данных, полученных на 2-м и 3-м шагах. Для выработки критерия или стандарта исходят из предположения, что концентрация должна быть такой, чтобы не мог быть нанесён вред здоровью $[3,10]$.

Первый этап: качественная идентификация опасностей. Это процесс выявления проблемы: например, выявляются источники загрязнения, потенциально опасные вредные вещества, их токсичность. При этом используются различные методы идентификации риска:

статистические, основанные на анализе накопленных статистических данных произошедших событий, их частоте повторения; 


\section{экология}

аналитические, базирующиеся на изучении причинно-следственных связей;

экспертные оценки событий, предполагающие оценку вероятностей проявления факторов экологической опасности.

Второй этап: определение границ зоны риска. В процесс количественной оценки опасности входит рассмотрение схемы максимально возможного потока вредного вещества и установление географических границ его воздействия, т.е. полного жизненного цикла продукта.

Третий этап: оценка путей воздействия стрессора. Он предусматривает рассмотрение общей схемы воздействия вредного вещества на биоту, а также прямое его воздействие на здоровье человека,в результате чего проводится количественная оценка между воздействующей дозойзагрязняющего вещества и случаями вредных эффектов, устанавливается зависимость «доза-эффект».

Четвертый этап: характеристика риска. С использованием количественных показателей, полученных напредыдущих этапах анализа, оцениваетсявероятность экологического риска для индивидуума, популяции или экосистемы вцелом, расчет значений риска для отдельных маршрутов и путей поступления вещества, проводится анализ неопределенности оценки риска.

Пятый этап: управление риском. Концепция оценки риска включает в себя два элемента: оценку риска и управление риском, и пятым завершающим этапом является управление риском. На этом этапе рассматривается совместимость финансовой выгоды с экологическими требованиями и вероятностью проявления экологического риска. Например, предлагаются варианты мероприятий по уменьшению риска:

- наиболее оперативные и сравнительно дешевые;

- оперативные и сравнительно дорогие;

- сравнительно дорогие;

- другие организационные мероприятия

В статье «Экологические риски в нефтедобывающей промышленности» [11] автор пишет, что «максимальная вероятность возникновения экологических рисков проектов разработки нефтяных месторождений имеет место в период строительства, на стадии постоянной добычи и на ликвидационной стадии. Степень влияния экологических рисков на результат проекта максимальна в период постоянно.

Существуют также следующие методы минимизации рисков:

- Передача рисков;

- Распределение рисков между участниками проекта;

- Удержание риска;

- Сокращение риска;

- Резервирование средств на покрытие непредвиденных расходов;

- Поглощение риска;

- Избежание (упразднение) рисков

Любой экологический риск следует рассматривать только в сочетании с конкретными экономическими и социальными условиями [12]. При недропользовании возникают риски, которые могут быть связаны как с неполучением ожидаемых результатов при изучении недр, так и с возможной поломкой или потерей дорогостоящей техники, что в обоих случаях приводит к нерациональным затратам финансовых 
и трудовых ресурсов. В связи с этим экологические риски при недропользовании можно связывать как с информационными несбывшимися ожиданиями, так и с материальными потерями. В первом случае из-за технических или технологических причин не может быть дана информация о недрах достаточной полноты и точности, необходимой для решения поставленной задачи, а во втором случае не будет получен планируемый материальный объект - не выявлено месторождение полезных ископаемых; не получено в достаточном количестве искомое минеральное сырье (разведанные запасы требуемой кондиции), а также понесены другие материальные потери разрушение используемой техники, зданий, сооружений и др.»

Согласно [6] риски делятся на 2 группы: Геологические риски и экологические риски. Геологические риски в свою очередь подразделяются на 2 категории. Первая касается геологоразведочных работ, особенно на новых и слабоизученных объектах. Весь цикл разведочных работ, особенно бурение глубоких скважин, является очень дорогим «удовольствием», поэтому недропользователи пытаются до предела уменьшить эти затраты. Доля затрат на разведку и соответствующие объемы работ почти во всех крупных нефтяных компаниях являются очень низкими.

Вторая категория геологических рисков связана с разработкой месторождений. «Поршневой» принцип вытеснения нефти в пласте не обеспечивает эффективную перколяцию. Следует иметь в виду, что масштабная закачка «инородной» воды резко и необратимо изменяет минералогический состав продуктивного пласта и соответственно все природные свойства коллектора, т. е. происходит активный техногенный метасоматоз с отрицательным эффектом. Закритические режимы разработки нефтяных месторождений возмущают геологическую среду и создают многочисленные точки бифуркаций в глубинных недрах и на поверхности, что предопределяет геологические риски.

Экологические риски при добыче нефти связаны в первую очередь с тем, что такая гигантская техногенная нагрузка инициирует проявление геодинамических процессов природно-техногенного генезиса, имеющих место в пределах данного и других месторождений, а также оказывает воздействие на почвы, поверхностные и подземные воды.

В статье «Экологические риски в системе нормативно-правовой базы Республики Казахстан» [9] автор разъясняет, что добыча и транспортировка нефти и газа относятся к разряду потенциально опасных производств, а соответствующие объекты являются объектами повышенного риска. Они обладают колоссальными возможностями по воздействию на окружающую среду и население (изменение ландшафта, загрязнение объектов природной среды, вредное воздействие на организмы человека и животных). Наиболее концентрированное и масштабное негативное воздействие происходит при авариях. В таких ситуациях чрезвычайно важна роль законодательных и нормативных документов, которые должны содержать гарантии и критерии недопущения чрезвычайных ситуаций, а в случае критического положения предусматривать действенные меры выхода из них с минимизацией возможных потерь.

Анализ казахстанской законодательной и нормативной документации [9, 12 , 14] показал, что к настоящему времени в республиканском природоохранном законодательстве сложилась довольно сложная ситуация с определением таких ос- 
новополагающих понятий, как «экологическая опасность», «экологически опасная деятельность», «экологически опасный объект», «экологический риск», «оценка риска», «управление риском», управление безопасностью». Это приводит к значительным трудностям во взаимоотношениях между контролирующими органами и компаниями, осуществляющими связанные с риском нефтегазовые операции.

Если проблемы промышленной безопасности в определенной мере отрегулированы правовыми нормами промышленной безопасности, то вопросы экологической безопасности являются открытым полем, которое требует скорейшего освоения и своего нормативно-законодательного оформления [1].

Таким образом, международный и казахстанский опыт в области анализа, оценки и управления экологическими рисками убедительно показывает, что с каждым годом решение таких задач становится все более актуальным не только для общества в целом, но и для отдельных организаций, являющихся объектами недропользования.

\section{ЛИТЕРАТУРА}

1 Елюбаев Ж.С. Экологические риски в сфере недропользования: законодательство и практика - Режим доступа: http://online.zakon.kz/Document/?doc_id=31449738 [Elyubaev Zh.S. Ekologicheskie riski v sfere nedropol'zovaniya: zakonodatel'stvo i praktika Rezhim dostupa: http://online.zakon.kz/Document/?doc_id=31449738]

2 Шлегель О.В. Управление экологическими рисками на предприятиях нестяной отрасли // Российское предпринимательство. - 2011. - № 11 (2). - С. 92-97. [Shlegel' O.V. Upravlenie ekologicheskimi riskami na predpriyatiyah neftyanoj otrasli // Rossijskoe predprinimatel'stvo. - 2011. - № 11 (2). - S. 92-97.]

3 Торегожина Ж.Р., Жунусова М.А. Қауіпсіздік және тәуекел; оқу-әдістемелік қүралы-Алматы; Қазақ университеті, 2012.-163бет [Toregozhina Zh.R., Zhunusova M.A. Қauipsizdik zhəne təuekel; оқu-ədistemelik қүraly-Almaty; Қаzaқ universiteti, 2012.-163bet]

4 Ехлаков Ю.П., Переметина Т.О. Методика оценки экологического риска при добыче и транспортировке нефти. https://сyberleninka.ru/article/n/metodika-otsenkiekologicheskogo-riska-pri-dobyche-i-transportirovke-nefti/viewer [Ekhlakov YU.P., Peremetina T.O. Metodika ocenki ekologicheskogo riska pri dobyche i transportirovke nefti. https://cyberleninka.ru/article/n/metodika-otsenki-ekologicheskogo-riska-pri-dobychei-transportirovke-nefti/viewer]

5 Касьяненко А.А. Современные методы оценки рисков в экологии. Учебное пособие. М.: Изд-во РУДН 2008. - 271 с. [Kas'yanenko A.A. Sovremennye metody ocenki riskov v ekologii. Uchebnoe posobie. - M.: Izd-vo RUDN 2008. - 271 s.]

6 Хаустов А.П., Редина М.М., Силаева П.Ю. Экологическое проектирование и риск-анализ. - М.: РУДН, 2008. - 320 с. [Haustov A.P., Redina M.M., Silaeva P.Yu. Ekologicheskoe proektirovanie i risk-analiz. - M.: RUDN, 2008. - 320 s.]

7 Экологический кодекс Республики Казахстан от 2 января 2007 г. № 212-III РК [Ekologicheskij kodeks Respubliki Kazahstan ot 2 yanvarya 2007 g. № 212-III RK.]

8 Карандашева Т.К. Методы анализа экологического риска - Вологда: ВГТУ, 2012. - 36 c. [Karandasheva T.K. Metody analiza ekologicheskogo riska - Vologda: VGTU, 2012. $36 \mathrm{s.}]$

9 Руденко И. Экологические риски в системе нормативно-правовой базы Республики Казахстан. II Атырауский правовой семинар «Актуальные вопросы и анализ практики применения законодательства в нефтегазовой отрасли Республики Казахстан», Атырау, 9 апреля 2004 г. [Rudenko I. Ekologicheskie riski v sisteme normativno-pravovoj 
bazy Respubliki Kazahstan. II Atyrauskij pravovoj seminar «Aktual'nye voprosy i analiz praktiki primeneniya zakonodatel'stva v neftegazovoj otrasli Respubliki Kazahstan», Atyrau, 9 aprelya 2004 g.]

10 Меньшиков В.В., Швыряев А.А. Анализ риска при систематическом загрязнении атмосферного воздуха опасными химическими веществами: Учебное пособие. -М.: Изд-во МГУ, 2003. [Men'shikov V.V., Shvyryaev A.A. Analiz riska pri sistematicheskom zagryaznenii atmosfernogo vozduha opasnymi himicheskimi veshchestvami: Uchebnoe posobie. - M.: Izd-vo MGU, 2003.]

11 Сабирова А.Р., Адильханова А.К. Экологическая оценка влияния загрязнений на окружающую среду в Мангистауской области // Вестник Каз. Академии транспорта и коммуникации. - 2010. - №5 (66). - C. 263-266. [Sabirova A.R., Adil'hanova A.K. Ekologicheskaya ocenka vliyaniya zagryaznenij na okruzhayushchuyu sredu v Mangistauskoj oblasti // Vestnik Kaz. Akademii transporta i kommunikacii. - 2010. - №5 (66). - S. 263-266.]

12 Байдельдинов Д.Л., Акопова Э.А. Экологическая безопасность и риски в сфере недропользования // Вестник КазНУ. Серия Юридическая. № 3 (67). 2013 - С. 124-128. [Bajdel'dinov D.L., Akopova E.A. Ekologicheskaya bezopasnost' i riski v sfere nedropol'zovaniya // Vestnik KazNU. Seriya Yuridicheskaya. № 3 (67). 2013 - S. 124-128]

13 Zh. Zholmahan, Some questions in the environmental risks in the subsoil // KazNU Bulletin. Lawsereies. - 2014. - №3 (71). - P. 213-215.

14 Музалевский А.А., Карлин Л.Н. Экологические риски. Теория и практика. - СПб.: РГГMY, 2011. - 446 c. [Muzalevskij A.A., Karlin L.N. Ekologicheskie riski. Teoriya i praktika. $\mathrm{SPb} .:$ RGGMU, 2011. - $446 \mathrm{~s}$. 